Available online on 15.09.2018 at http://jddtonline.info Journal of Drug Delivery and Therapeutics

Open Access to Pharmaceutical and Medical Research

C 2011-18, publisher and licensee JDDT, This is an Open Access article which permits unrestricted non-commercial use, provided the original work is properly cited

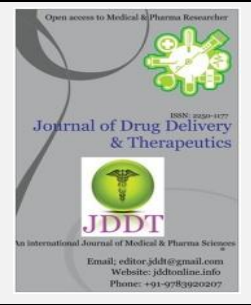

Open $\odot$ Access

Research Article

\title{
QUERCETIN NANOPARTICLES REPRESSED LIVER AND BRAIN TOXICITIES INDUCED BY TARTRAZINE IN RATS
}

\author{
Eman G. Mohamed ${ }^{1}$, Ibrahim M. Abo-laila ${ }^{1}$, Hassan A.M. Hendawy ${ }^{-2}$ \& Ebtehal Mohammad F. ${ }^{*} *$ \\ ${ }^{1}$ Molecular Drug Evaluation Department, National Organization for Drug Control and Research (NODCAR), Giza, Egypt. \\ ${ }^{2}$ Analytical and Inorganic Chemistry Department, National Organization for Drug Control and Research (NODCAR), Giza, Egypt. \\ ${ }^{3}$ Pharmacology Department, National Organization for Drug Control and Research (NODCAR), Giza, Egypt. P.O. BOX 29
}

\begin{abstract}
Tartrazine (TZ) is an azobenzene artificial yellow dye for foods, drugs, and cosmetics. Quercetin is member of the flavonoid family. The current study investigated the protective effect of quercetin nanoparticles (QNPs) against TZ. Male albino rats were divided into group1: control, group 2: TZ (50 mg/kg), group 3: QNPs $(5 \mathrm{mg} / \mathrm{kg})$, and group 4: QNPs+TZ. The results of the present study revealed that, the oral administration of TZ dye caused significantly increased liver biomarkers. Also, a marked effect on lipid profile and blood parameters was shown. In addition TZ induced an elevation in the examined oxidative stress biomarkers and decrease in glutathione peroxidases and acetylcholine esterase. TZ diminished exploration and rearing in open field test as well as elevation in GABA content and apoptosis as well as changes in tissues by histopathological examination. In fact, the results showed good influence of QNPs in improving injuries associated with TZ administration.
\end{abstract}

Keywords: Tartrazine Dye, Quercetin Nanoparticles, Liver-Brain injuries.

Article Info: Received 18 July, 2018; Review Completed 11 Aug 2018; Accepted 15 Aug 2018; Available online 15 Sep 2018

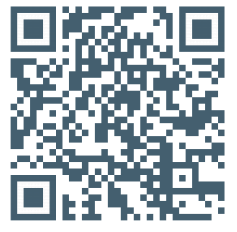

\section{Cite this article as:}

Eman MG, Ibrahim AM, Hassan HAM, Ebtehal MF, Quercetin nanoparticles repressed liver and brain toxicities induced by tartrazine in rats, Journal of Drug Delivery and Therapeutics. 2018; 8(5):230-240 DOI: http://dx.doi.org/10.22270/iddt.v8i5.1865

\section{*Address for Correspondence:}

Ebtehal Mohammad F, Pharmacology Department, National Organization for Drug Control and Research (NODCAR), Giza, Egypt. P.O. BOX 29

\section{INTRODUCTION}

A wide sort of food additives, running into more than 2,500 items used to preserve, dye or enhance foods $\mathbf{1 , 2 , 3}$ are a consequence of industrialization and the development of food processing technology. They are approved for human utilization after studying its acute, sub-acute and chronic toxicities. The individual response varies not only according to dose, age, gender, nutritional status and genetic factors, but also according to long term disclosure to low doses $4, \mathbf{5 , 6 , 7}$.

Numerous metabolites of these substances, such as nitrous compounds, have been found to be carcinogens. Toxicity or benefit depends on to what degree food components affect absorption, excretion or the metabolism as a whole. Because there may be interaction between different substances, the clarity of adequate safety limits for human consumption is further compounded ${ }^{\mathbf{8 , 9}}$.

Tartrazine (TZ) is an azobenzene artificial yellow dye whose structure features a tri-sodium salt of 3carboxy-5-hydroxy-1 (p-sulfophenyl) -4(sulfophenylazo) pirazolone. It is extensively used to dye sweets, chewing gum, jellies, puddings, juices, jams, mustard, sodas, drugs and cosmetics. It is reduced in the individual to an aromatic amine which is highly sensitizing. Its main metabolite identified to date is sulfanylic acid $10,11,12,13$. 
Tartrazine is used as the food additive, most often responsible for allergic reactions. Although urticaria, asthma, purpura and eczema have been described, essentially affecting individuals allergy to aspirin, the underlying immunologic mechanism has proved elusive. Some studies have suggested a humoral immune response brought about by the sulfanyl group 14, 15, 16, 17. Some countries such as Sweden, Switzerland and Norway have withdrawn TZ on the basis of its anaphylactic potential ${ }^{\mathbf{1 8}}$. Several authors have studied the carcinogenetic and mutagenetic properties of $\mathrm{TZ} \mathbf{1 9 , 2 0 , 2 1 , 2 2 , 7}$.

Quercetin is members of the flavonoid family ${ }^{23}$. It has anti-cancerogenic, antiviral, anti-ischemic, antiinflammatory and antiallergenic, as well as defensive influence in atherosclerosis and coronary heart disease ${ }^{\mathbf{2 4}}$. Actually flavonoids can prevent oxidative damage as a result of their ability to scavenge reactive oxygen species ${ }^{25}$ and metal chelating ${ }^{\mathbf{2 6}}$. Noteworthy, quercetin present in the human diet as vegetables, herbs and edible fruits. Even with the medicinal benefits of quercetin, it has low bioavailability (less than $17 \%$ in rats and even $1 \%$ in human) ${ }^{27}$ due to its reduced aqueous solubility, as a result, the clinical application of this drug greatly restricted. Hence, it becomes necessary to build up a system which could increase the solubility of quercetin.

Nanoparticles are mainly suitable for drug delivery for water insoluble compounds such as quercetin ${ }^{27}$. According to Noyes-Whitney equation a decrease in particle size will lead to an increase in effective surface area which results in enhanced bioavailability ${ }^{28}$.

In fact, the body has defense mechanisms against oxidative damage which are composed of enzymatic and non-enzymatic systems ${ }^{29}$. The enzymatic mechanism is made of free radical scavengers like catalase (CAT), superoxide dismutase (SOD) and the glutathione-depend enzymes such as glutathioneperoxidase (GPx), and glutathione-Stransferase ${ }^{30,31}$. The non-enzymatic mechanism involves certain endogenous compounds in the body as reduced glutathione (GSH) and certain exogenous compounds taken as vitamins $\mathrm{E}$ and $\mathrm{C}$, and flavonoids ${ }^{29,23}$.

The aim of this study was to determine the effect of $\mathrm{TZ}$ exposure on male albino rats and to assess whether these effects can be ameliorated by quercetin nanoparticles (QNPs) two hours after TZ.

\section{MATERIAL AND METHODS}

\section{Materials}

Food colors additives Tartrazine yellow (E102) was obtained from the local market and administered orally according to Walton et al. (1999) ${ }^{22}$. Chitosan $(\mathrm{CH})$, medium molecular weight and viscosity 190-310 kDa, acetic acid, tripolyphosphate (TPP) and Quercetin nanoparticles powder with an average particle diameter of about $45 \mathrm{~nm}$ were obtained from Sigma Chemical Co. (St. Louis, MO, USA). Alanine aminotransferase (ALT) and Aspartate aminotransferase (AST) kits were purchased from Spectrum-diagnostics Co. (Cairo,
Egypt). Alkaline phosphatase (ALP), and acetylcholine esterase (AChE) kits were obtained from Diamond diagnostics. Glutathione peroxidase (GPx) kit was obtained from Randox diagnostics. Reactive oxygen species (ROS), lipid peroxidation (LPO), and protein carbonyl (PC), were obtained from Sigma Chemical Company (preparation in lab) according to method in paper.

All other chemicals used throughout the experiments were of the highest analytical grade available.

\section{Preparation of CH /QNPs}

A sequence of $\mathrm{CH} / \mathrm{QNPs}$ beads were prepared based on were prepared by ionic cross-linking as the following method. Typically, $1.0 \mathrm{~g}$ of $\mathrm{CH}$ was dissolved using magnetic stirring in $50 \mathrm{~mL}$ of $0.1 \mathrm{M}$ acetic acid at $25^{\circ} \mathrm{C}$ for $20 \mathrm{~min}$ until complete dissolved and viscose homogenous solution was obtained. Various amounts of QNPs; 0, 5\%, 10\% and 15\% dispersed in $10 \mathrm{~mL}$ of distilled water were added slowly into the above $\mathrm{CH}$ solution. The obtained mixture was further stirred for $10 \mathrm{~min}$ to obtain a homogenous system. Subsequently, the solution was extruded in the form of dewdrops, using a syringe (2 $\mathrm{mm}$ diameter), into a solution $(50 \mathrm{ml})$ containing TPP $(3.0 \mathrm{~g})$ and $\mathrm{NaOH}(2.0 \mathrm{~g})$. The beads were remained in the mixture of solution overnight so as to crosslink with TPP. The $\mathrm{pH}$ of the suspension was adjusted to 5 by adding $0.1 \mathrm{M} \mathrm{NaOH}$ and the stirring was continued for another $30 \mathrm{~min}$. without $\mathrm{pH}$ adjustment.

\section{Experimental Animals}

Adult male albino rats (40 animals) weighing between $195 \pm 10 \mathrm{~g}$ were used in the present study. The rats were obtained from the animal house of the National Organization for Drug Control and Research Egypt (NODCAR). The animals were kept under standard laboratory conditions of light/dark cycle (12/12 h), temperature $\left(20-25^{\circ} \mathrm{C}\right)$, and allowed free access to food (standard pellet diet), water ad libitum for one week. Animals were treated gently; squeezing, pressure and tough maneuver were avoided. The investigation was complied with the Guide for Care and Use of Laboratory Animals of the National Institutes of Health (NIH publication No. 85-23, revised 1996).

\section{Experimental design}

Rats were randomly divided into four groups $(n=10)$. Groups were treated as follows:

Control group rats were administrated with one $\mathrm{ml}$ saline solution.TZ group was given $\mathrm{TZ}(50 \mathrm{mg} / \mathrm{kg}$, orally). QNPs group was given $(5 \mathrm{mg} / \mathrm{kg}$, orally). Rats of the protective groups were given $(50 \mathrm{mg} \mathrm{TZ}+5 \mathrm{mg}$ QNPs, orally). The administered QNPs and TZ were given for 30 days.

\section{Behavioral test; open field test:}

Open field test was carried out at the end of the treatment period according to Sethi et al, (2008) ${ }^{32}$, where the latency time, ambulation frequency, grooming frequency, and rearing frequency were measured. 


\section{Sample preparation}

At the end of the experimental period, all rats were fasted for 12 hours and then the blood samples were collected from venous sinus in centrifuge tubes to separate serum by centrifugation at $3000 \mathrm{rpm}$ for 15 minutes. Sera were kept at $-80^{\circ} \mathrm{C}$ for biochemical analyses. In addition, the liver and the cerebellum were dissected and isolated immediately, plotted free from adhering blood, and dried between two filter papers. Each tissue sample was then weighed. Parts from liver and cerebellum were kept in $10 \%$ formalin to examine histologically and the other parts were kept at $-80^{\circ} \mathrm{C}$ for biochemical examination in liver and cerebellum tissues.

\section{Biochemical analysis}

\section{1- Measurement of blood parameters}

Hemoglobin ( $\mathrm{Hb} \%)$ concentration, red blood cell (RBC) count and hematocrit (HCT\%) were estimation using a semiautomatic hematological analyzer (SWELAB IEO Model). The auto counter utilized $20 \mu \mathrm{l}$ of blood in $16 \mathrm{ml}$ of a commercially prepared diluent. The machine's ability to count cells was based on the principle of electronic impedance. In addition, serum glucose level was as described by Trinder, (1969) method ${ }^{33}$.

\section{2- Measurement of liver functions}

Determination of aspartate aminotransferase (AST) and alanine aminotransferase (ALT) activities were performed according to the method of Reitman and Frankel, (1957) ${ }^{34}$. Determination of alkaline phosphatase (ALP) was determined in serum according to the method of was determined by Belfield and Goldberg, (1971) ${ }^{35}$.

\section{3- Measurement of Lipid profile}

Serum LDL-cholesterol concentration was estimated by the method of Wieland and Seidel, (1983) ${ }^{36}$, for enzymatic colorimetric method. Serum HDL concentration was estimated by the method of Burstein et al, ( 1970$)^{37}$, for enzymatic colorimetric method. Besides, serum cholesterol and triglyceride concentration were estimated by the method described by Zollner and Kirsch, (1962) $\mathbf{3 8}$ that is an enzymatic colorimetric method.

\section{4- Measurement of reactive oxygen species (ROS) content.}

A modified version of a previously described assay for the intracellular conversion of nitro blue tetrazolium (NBT) to form azan by superoxide anion was used to measure the generation of reactive oxygen species ${ }^{39}$.

\section{5- Measurement of malondialdehyde content}

Lipid peroxides formation was determined in liver and cerebellum homogenates as thiobarbituric acid reactive substances (TBARS). It was determined according to the method of (Uchiyama and Mihara, 1978) ${ }^{40}$.
3.6- Measurement of glutathione peroxidase (GPx) activity:

Glutathione peroxidase activity determined in liver and cerebellum homogenates according to the method of (Brigelius-Flohe, 1999) ${ }^{41}$.

\section{7- Measurement of Protein Carbonyl Concentration:}

Protein carbonyl concentration was measured in liver and cerebellum by first forming labeled protein hydrazone derivatives using 2, 4-dinitrophenyl hydrazide ${ }^{42}$.

\section{8- Measurement of Myelopreoxidase (MPO) Activity}

Myeloperoxidase activity was evaluated in liver and brain tissues according to Bradley et al, (1982) ${ }^{43}$.

\section{9- Measurement of acetyl cholinesterase (ACHE) activity}

The Procedure used for the determination of Cholinesterase activity in the cerebellum of rats is a modification of the method of Ellman et al, (1961) ${ }^{44}$ as described by Gorun et al, (1978) ${ }^{45}$. The principle of the method is the measurement of the rate of production of thiocholine as a result of acetylthiochline hydrolysis.

\subsection{0- Determination of GABA, 5-HT, NE and DA contents}

Cerebellum gamma-aminobutyric acid (GABA), serotonin (5-HT), norepinephrin (NE) and dopamine (DA) were estimated according to method of Ciarlone (1978) ${ }^{46}$. The method is based on fluorometric test in which fluorescent product results from reaction with orthophthalaldehyde solution in case of 5-HT and reaction with alkaline sulfite and iodine solution in case of NE and DA.

3.11- Brain (cerebellum) and liver Caspase 3 Immunohistochemical Examinations

Paraffinized brain (cerebellum) and liver sections were deparaffinized and rehydrated through xylene and alcohol for immunohistochemical assessment of Caspase 3. Antigen unmasking was performed by incubating the sections for $20 \mathrm{~min}$ in citrate buffer (Thermo Fisher Scientific, Fremont, CA; pH 6.0) at the boiling point then cooled. Sections were then incubated overnight at $4{ }^{\circ} \mathrm{C}$ either with the rabbit polyclonal antiCaspase 3 (1:200; Thermo Fisher Scientific) primary antibody. After washing with PBS, the slides were incubated for $30 \mathrm{~min}$ at $37{ }^{\circ} \mathrm{C}$ with the biotinylated secondary antibody then with the Vector Elite ABC kit (Elite reagent Avidin DH and biotinylated horseradish peroxidase $\mathrm{H}$ reagents; Vector Laboratories Inc., Burlingame, C A). After another wash with PBS, the antibody-biotin-avidin-peroxidase complex was developed using diaminobenzidinetetrahydrochloride (DAB Substrate K it, Vector Laboratories I nc.). Sections were counterstained with hematoxylin, dehydrated, and cleared in xylene then cover slipped, where the reaction appeared as a brown cytoplasmic reaction $(400 \times)$. 


\section{Methodology of image morphometry for inspection of the slides}

Images of histological sections were analyzed by Image $\mathbf{J}$ software to measure the optical density of the apoptotic area ${ }^{47}$.

\subsection{2- Histopathological examination of cerebellum and liver tissues}

For histopathological examination, a liver and cerebellum tissue was dissected and tissue samples were fixed in $10 \%$ neutral formalin for $24 \mathrm{~h}$. Then samples were processed using a graded ethanol series and embedded in paraffin. Paraffin sections were cut into $6 \mu \mathrm{m}$-thick slices and stained with hematoxylin and eosin for light microscopic examination.

\section{Statistical analysis}

Results were expressed as mean \pm SEM. Statistical analysis was carried out using one-way analysis of variance (ANOVA) followed by Tukey-Kramer Multiple Comparison Test. Probability values of less than 0.05 were considered statistically significant. Whereas the graphs were drawn using a prism computer program (GraphPad software Inc. V5, San Diego, CA).

\section{RESULTS}

\section{Characterization of QNPs:}

Figure (A\&B), showed morphology and size of QNPs using SEM photographs. QNPs exhibited particles uniformity in size, less crystallinity, and absence of larger particles (Figure A). As depicted in the image, the particles possessed uniform shape. The size of all particles was found to be less than $200 \mathrm{~nm}$ (Figure B).

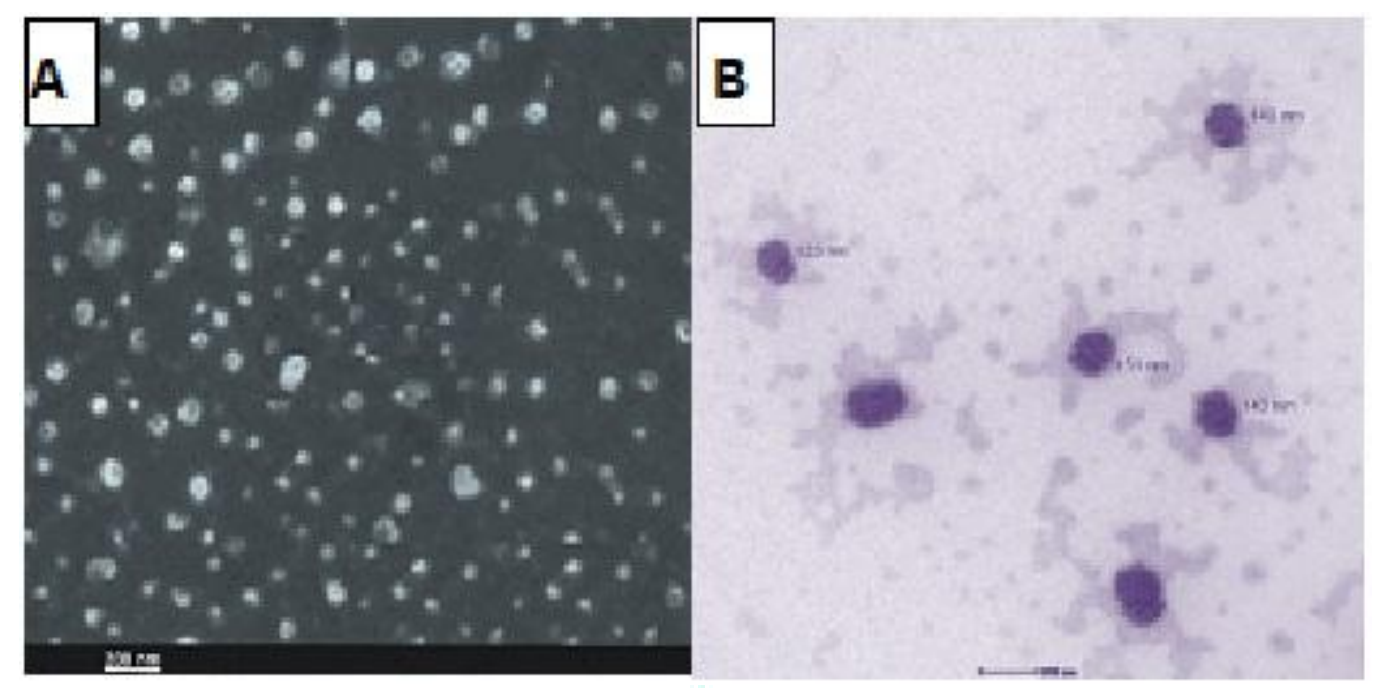

Figure (A\&B): Photomicrographs \& investigation of morphology and size of QNPs using SEM photographs.

\section{Effect of QNPs on TZ induced behavioral alteration; open field test:}

Figure (1), illustrated the parameters related to the open field test. Noteworthy, the latency time (Figure 1A) increased significantly to 3 folds in TZ group as compared to control group, whereas QNPs alone and as treatment (QNPs+TZ group) induced significant decreases in the time (63\% and 59\%, respectively) as compared to $\mathrm{TZ}$ group. On the other hand the ambulation frequency (Figure 1B) decreased significantly by $45 \%$ in TZ group as compared to control group. While the ambulation frequencies were augmented in QNPs and QNPs +TZ groups (nearly to 2 folds) as compared to $\mathrm{TZ}$ group. In addition, $\mathrm{TZ}$ decreased the grooming frequency (Figure 1C) by $62 \%$ as compared to control group, whilst the grooming frequencies were incremented in QNPs and QNPs +TZ groups (nearly to 2 folds) as compared to TZ group. Also the rearing frequency (Figure 1D) was decreased significantly by $26 \%$ as compared to control group, but it was increased significantly in QNPs $+\mathrm{TZ}$ group by $27 \%$ as compared to $\mathrm{TZ}$ group. 


\section{Figure 1}

A
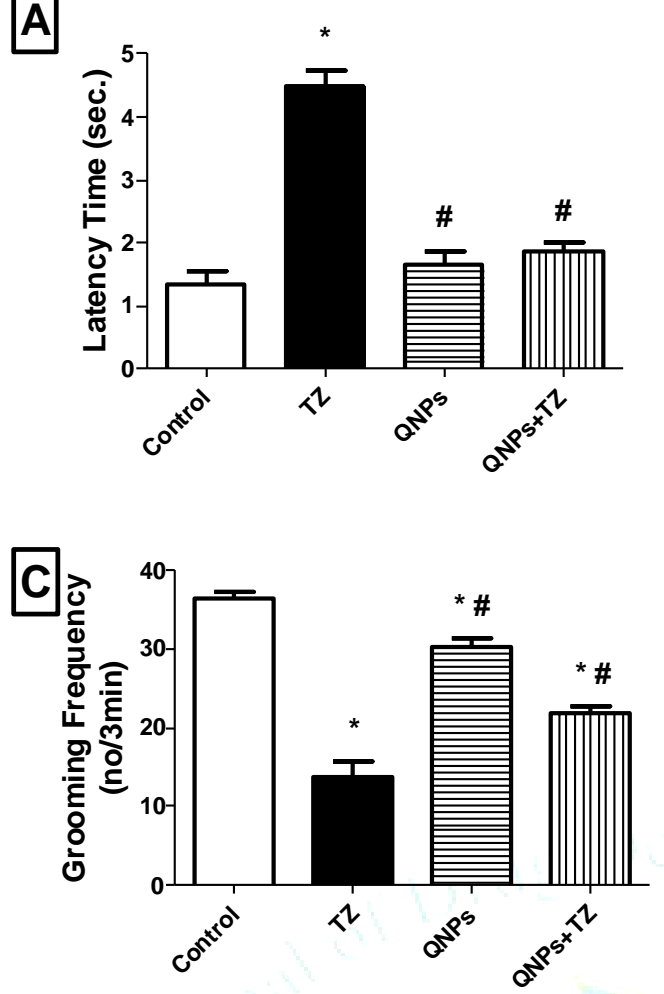

B
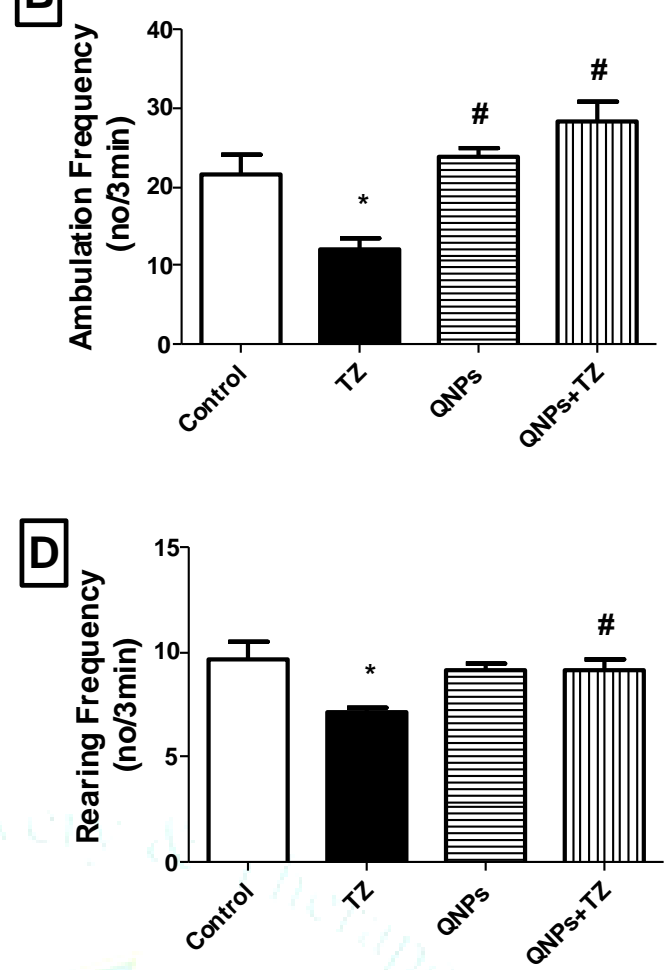

Figure 1: Effects of QNPs (5mg) on latency [A] , ambulation frequency [B], grooming frequency [C], and rearing frequency [D] of open field behavioral test in TZ $(50 \mathrm{mg} / \mathrm{kg})$ induced brain injury in rats.

Data represents mean $(\mathrm{n}=8-10) \pm \mathrm{SEM},{ }^{*}{ }^{\#} \mathrm{P}<0.05$ relative to Control \& TZ groups, respectively. Statistical analysis was carried out by one way ANOVA followed by Tukey- Kramer Multiple Comparison Test.

Evaluation of Body weight, blood parameters $(\mathrm{Hb} \%$, RBCs, and HCT \%) and serum glucose level

The obtained data in table (1) revealed that, administration of QNPs alone reduced the body weight significantly compared to $\mathrm{TZ}$ group by $16 \%$. Also the obtained results showed that, administration of QNPs + $\mathrm{TZ}$ decreased the body weight significantly compared to TZ group by $14 \%$.

Table (1) investigated that $\mathrm{TZ}$ significantly reduced $\mathrm{Hb} \%$, RBCs, and HCT\% by $24 \%, 24 \%$ and $26 \%$, respectively, compared to control group. Besides TZ induced increment in serum glucose level by $41 \%$ as compared to control group. In contrary, administration of QNPs alone almost didn't change $\mathrm{Hb} \%$, RBCs, and HCT\% as compared to control group, but as compared to TZ group QNPs increased these parameters by $33 \%$, $33 \%$ and $32 \%$, respectively. As well QNPs reduced the serum glucose level compared to $\mathrm{TZ}$ group by $65 \%$. Noteworthy, administration of QNPs + TZ revealed significant increased in $\mathrm{Hb} \%$, and RBCs as compared to TZ group by $28 \%$ and $26 \%$, respectively. Moreover administration of QNPs $+\mathrm{TZ}$ reduced the serum glucose level compared to TZ group by $15 \%$.

Table (1) Ameliorative effects of quercetin nanoparticles against tartrazine toxicity on the body weight and blood parameters (Hb\%, RBCs, and HCT \%) and serum glucose level:

\begin{tabular}{|c|c|c|c|c|c|c|}
\hline \multirow[b]{2}{*}{ Parameters } & \multicolumn{2}{|c|}{ Body weight (g) } & \multicolumn{3}{|l|}{ Hematology } & \multirow{2}{*}{$\begin{array}{r}\text { Glucose } \\
\text { (mg/dl) }\end{array}$} \\
\hline & Initial & Final & $\mathbf{H b \%}$ & $\operatorname{RBCs}\left(10^{6} / \mathrm{mm}^{3}\right)$ & HCT (\%) & \\
\hline Control & $195.5 \pm 1.50$ & $262.0 \pm 2.17$ & $14.81 \pm 0.35$ & $5.10 \pm 0.32$ & $46.00 \pm 0.53$ & $96.00 \pm 0.38$ \\
\hline $\begin{array}{l}T Z \\
(50 \mathrm{mg} / \mathrm{kg}) \\
\end{array}$ & $196.5 \pm 2.18$ & $310.5 \pm 2.83^{*}$ & $11.20 \pm 0.41 *$ & $3.90 \pm 0.20 *$ & $34.00 \pm 0.41 *$ & $135.00 \pm 0.69 *$ \\
\hline $\begin{array}{l}\text { QNPs } \\
(5 \mathrm{mg} / \mathrm{kg})\end{array}$ & $194.5 \pm 2.15$ & $261.0 \pm 2.42^{\#}$ & $14.84 \pm 0.18^{\#}$ & $5.20 \pm 0.24^{\#}$ & $45.00 \pm 0.52^{\#}$ & $94.00 \pm 0.47^{\#}$ \\
\hline QNPs + TZ & $197.0 \pm 2.45$ & $266.0 \pm 1.83^{\#}$ & $14.37 \pm 0.27^{\#}$ & $4.90 \pm 0.19^{\#}$ & $35.00 \pm 0.63$ & $115.00 \pm 0.58^{\#}$ \\
\hline
\end{tabular}

Values are expressed as mean \pm S.E. ${ }^{* \#} p<0.05$ relative to control \& TZ groups, respectively. TZ= tartrazine, QNPs $=$ quercetin nanoparticles. 
Effect of QNPs on TZ induced toxicity on AST, ALT and ALP levels:

Table (2) illustrated that administration of QNPs alone reduced levels of AST, ALT and ALP as compared to
TZ group by $42 \%, 53 \%$ and $67 \%$, respectively. As well administration of QNPs + TZ revealed significant decreased in AST, ALT and ALP levels as compared to TZ group by $38 \%, 50 \%$ and $63 \%$, respectively.

Table (2) Ameliorative effects of quercetin nanoparticles against tartrazine toxicity on AST, ALT and ALP levels in rats.

\begin{tabular}{|c|c|c|c|}
\hline Parameters & AST (U/mL) & ALT (U/mL) & ALP (U/mL) \\
\hline Control & $38.57 \pm 2.83$ & $58.17 \pm 4.21$ & $50.08 \pm 5.23$ \\
\hline TZ (50 mg/kg) & $63.42 \pm 2.61^{*}$ & $121.0 \pm 4.18^{*}$ & $148.63 \pm 5.31^{*}$ \\
\hline QNPs (5mg/kg) & $36.92 \pm 2.44^{\#}$ & $56.41 \pm 3.96^{\#}$ & $49.73 \pm 5.18^{\#}$ \\
\hline QNPs + TZ & $39.14 \pm 2.38^{\#}$ & $60.39 \pm 4.17^{\#}$ & $54.81 \pm 4.92^{\#}$ \\
\hline
\end{tabular}

Values are expressed as mean \pm S.E. ${ }^{* \#} p<0.05$ relative to control \& TZ groups, respectively. TZ= tartrazine, QNPs $=$ quercetin nanoparticles.

Effect of quercetin nanoparticles against Tartrazineinduced lipid profile markers

Data in table (3) showed that administration of QNPs alone reduced levels of serum total cholesterol, triglyceride and LDL-C as compared to TZ group by $35 \%, 55 \%$ and $38 \%$, respectively. On other hand, QNPs administration, as compared to $\mathrm{TZ}$ administration, raised HDL-C level by 67\%. Besides, administration of QNPs $+\mathrm{TZ}$ revealed significant decreased in levels of serum total cholesterol, triglyceride and LDL-C as compared to TZ group by $34 \%, 49 \%$ and $27 \%$, respectively. In addition, administration of QNPs + TZ increased HDL$\mathrm{C}$ level by $35 \%$ as compared to $\mathrm{TZ}$ alone.

Table 3: Ameliorative effects of quercetin nanoparticles against tartrazine affected lipid profile in serum rat.

\begin{tabular}{|l|l|l|l|l|}
\hline Parameters & $\begin{array}{l}\text { Cholesterol } \\
(\mathbf{m g} / \mathbf{d L})\end{array}$ & $\begin{array}{l}\text { Triglyceride } \\
(\mathbf{m g} / \mathbf{d L})\end{array}$ & $\begin{array}{l}\text { HDL-Cholesterol } \\
\text { (mg/dL) }\end{array}$ & $\begin{array}{l}\text { LDL- Cholesterol } \\
(\mathbf{m g} / \mathbf{d L})\end{array}$ \\
\hline Control & $83.80 \pm 2.76$ & $68.9 \pm 2.84$ & $32.56 \pm 0.80$ & $41.24 \pm 0.82$ \\
\hline TZ $\mathbf{5 0} \mathbf{~ m g / k g )}$ & $128.36 \pm 2.44^{*}$ & $141.0 \pm 1.84^{*}$ & $21.41 \pm 0.51^{*}$ & $61.18 \pm 0.59^{*}$ \\
\hline QNPs (5mg/kg) & $83.44 \pm 2.31^{\#}$ & $63.9 \pm 1.84^{\#}$ & $35.81 \pm 0.62^{\#}$ & $38.22 \pm 0.61^{\#}$ \\
\hline QNPs + TZ & $85.27 \pm 2.23^{\#}$ & $71.4 \pm 1.84^{\#}$ & $28.91 \pm 0.43^{\#}$ & $44.71 \pm 0.68^{\#}$ \\
\hline
\end{tabular}

Values are expressed as mean \pm S.E. ${ }^{* \#} p<0.05$ relative to control \& TZ groups, respectively. TZ $=$ tartrazine, QNPs $=$ quercetin nanoparticles.

Evaluation of ROS, MDA, GPx, PC, and MPO in liver tissue

Table (4) investigated that TZ significantly augmented ROS, MDA, PC and MPO by $24 \%, 4$ folds, $26 \%$, and $39 \%$, respectively, compared to control group. Besides TZ reduced GPx by $40 \%$ as compared to control group. In contrary, administration of QNPs alone almost didn't change ROS, MDA, PC, and GPx as compared to control group, but as compared to TZ group QNPs decreased ROS, MDA, PC and MPO by 17\%, 77\%, $16 \%$, and $60 \%$, respectively. As well QNPs increased activity of GPx compared to TZ group by $68 \%$. Noteworthy, administration of QNPs + TZ revealed significant declined in ROS, MDA, PC and MPO by $18 \%, 75 \%, 23 \%$, and $52 \%$, respectively, as compared to TZ group. Furthermore administration of QNPs + TZ increased activity of GPx compared to TZ group by $69 \%$.

Table 4: Ameliorative effects of quercetin nanoparticles against tartrazine affected reactive oxygen species (ROS), malondialdehyde (MDA), and protein carbonyl (PC) contents as well as GPx and MPO activities in rat liver

\begin{tabular}{|c|c|c|c|c|c|}
\hline Parameters & $\begin{array}{c}\text { ROS } \\
(\boldsymbol{\mu m o l} / \mathbf{g} \text { tissue })\end{array}$ & $\begin{array}{c}\text { MDA } \\
(\mathbf{n m o l} / \mathbf{g} \text { tissue })\end{array}$ & $\begin{array}{c}\text { GPx } \\
(\text { IU/g tissue) }\end{array}$ & $\begin{array}{c}\text { PC } \\
(\mathbf{n m o l} / \mathbf{m g})\end{array}$ & $\begin{array}{c}\text { MPO } \\
\text { (U/g tissue) }\end{array}$ \\
\hline Control & $17.10 \pm 0.21$ & $9.84 \pm 0.08$ & $23.52 \pm 0.61$ & $25.0 \pm 0.61$ & $67.3 \pm 0.614$ \\
\hline $\begin{array}{c}\text { TZ } \\
(\mathbf{5 0} \mathbf{~ m g / k g})\end{array}$ & $21.28 \pm 0.44^{*}$ & $41.00 \pm 0.09^{*}$ & $14.21 \pm 0.31^{*}$ & $31.4 \pm 0.55^{*}$ & $93.2 \pm 1.4^{*}$ \\
\hline $\begin{array}{c}\mathbf{Q N P s} \\
\mathbf{( 5 m g / k g )}\end{array}$ & $17.65 \pm 0.21^{\#}$ & $9.43 \pm 0.09^{\#}$ & $23.90 \pm 0.61^{\#}$ & $24.30 \pm 0.51^{\#}$ & $37.4 \pm 1.82^{*}$ \\
\hline QNPs + TZ & $17.32 \pm 0.82^{\#}$ & $10.25 \pm 0.10^{\#}$ & $24.05 \pm 0.21^{\#}$ & $26.3 \pm 0.71^{\#}$ & $45.0 \pm 4.11^{* \#}$ \\
\hline
\end{tabular}

Values are expressed as mean \pm S.E. ${ }^{*} p<0.05$ relative to control \& $\mathrm{TZ}$ groups, respectively. $\mathrm{TZ}=$ tartrazine, QNPs $=$ quercetin nanoparticles. 
Evaluation of ROS, MDA, GPx, PC, MPO, and AchE in cerebellum tissue

Table (5) disclosed that TZ significantly augmented ROS, MDA, PC and MPO by 57\%, 5 folds, 33\%, and $79 \%$, respectively, compared to control group. Additionally $\mathrm{TZ}$ reduced GPx and $\mathrm{AChE}$ by $47 \%$, and $18 \%$, respectively, as compared to control group. In contrary, administration of QNPs alone almost didn't change ROS, MDA, GPx, PC, MPO, and AChE as compared to control group, but as compared to $\mathrm{TZ}$ group QNPs decreased ROS, MDA, PC and MPO by $37 \%, 80 \%, 25 \%$, and 28\%, respectively. As well QNPs increased activities of GPx and AChE compared to TZ group by $85 \%$, and 5\%, respectively. Moreover, administration of QNPs + TZ exposed significant declined in ROS, MDA, PC and MPO by $36 \%, 77 \%$, $21 \%$, and $29 \%$, respectively, as compared to $\mathrm{TZ}$ group. Furthermore, administration of QNPs + TZ increased activities of GPx and AChE compared to TZ group by $76 \%$ and $20 \%$, respectively.

Table 5: Ameliorative effects of quercetin nanoparticles against tartrazine affected reactive oxygen species (ROS), malondialdehyde (MDA), and protein carbonyl (PC) contents as well as GPx, MPO, and acetylcholine esterase (AChE) activities in rat cerebellum.

\begin{tabular}{|c|c|c|c|c|c|c|}
\hline Parameters & $\begin{array}{c}\text { ROS }(\boldsymbol{\mu m o l} \\
\text { /g tissue) }\end{array}$ & $\begin{array}{l}\text { MDA } \\
\text { (nmol/g tissue }\end{array}$ & $\begin{array}{c}\text { GPx } \\
\text { (IU/g tissue) }\end{array}$ & $\begin{array}{c}\text { PC } \\
(\mathbf{n m o l} / \mathbf{m g})\end{array}$ & $\begin{array}{c}\text { MPO } \\
(\mathbf{U} / \mathbf{g} \text { tissue) }\end{array}$ & $\begin{array}{c}\text { AChE } \\
\text { (U/g tissue) }\end{array}$ \\
\hline Control & $5.22 \pm 0.17$ & $8.61 \pm 0.21$ & $16.42 \pm 0.51$ & $19.09 \pm 0.43$ & $42.1 \pm 2.94$ & $628.43 \pm 2.45$ \\
\hline TZ $\mathbf{5 0 ~} \mathbf{~ m g / k g )}$ & $8.21 \pm 0.43^{*}$ & $40.2 \pm 0.16^{*}$ & $8.63 \pm 0.44^{*}$ & $25.32 \pm 0.15^{*}$ & $75.4 \pm 3.25^{*}$ & $513.20 \pm 4.21^{*}$ \\
\hline QNPs $\mathbf{5 m g} / \mathbf{k g})$ & $5.19 \pm 0.52^{\#}$ & $8.2 \pm 0.13^{\#}$ & $16.00 \pm 0.68^{\#}$ & $19.00 \pm 0.32^{\#}$ & $54.7 \pm 4.09^{\#}$ & $538.19 \pm 4.62^{\#}$ \\
\hline QNPs + TZ & $5.28 \pm 0.36^{\#}$ & $9.43 \pm 0.19^{\#}$ & $16.38 \pm 0.39^{\#}$ & $20.03 \pm 0.62^{\#}$ & $53.6 \pm 3.63^{\#}$ & $613.28 \pm 3.19^{\#}$ \\
\hline
\end{tabular}

Values are expressed as mean \pm S.E. ${ }^{* \#} p<0.05$ relative to control \& TZ groups, respectively. TZ $=$ tartrazine, QNPs $=$ quercetin nanoparticles.

\section{Effect on GABA, 5-HT, NE and DA contents}

Figure (2) showed that GABA content (Figure 2A) was increased significantly nearly to 2 folds as compared with control group, at the same time GABA contents were declined in QNPs and QNPs+TZ groups by 30\% and $15 \%$, respectively, as compared to $\mathrm{TZ}$ group. On the other hand, 5-HT contents (Figure 2B) were decreased significantly by $16 \%$ in TZ, and QNPs+TZ groups as well as $21 \%$ in QNPs as compared to control group. Conversely, NE (Figure 2C) and DA (Figure 2D) contents were increased significantly by $44 \%$ and $32 \%$, respectively, as compared with $\mathrm{TZ}$ group.

\section{Figure 2}

A

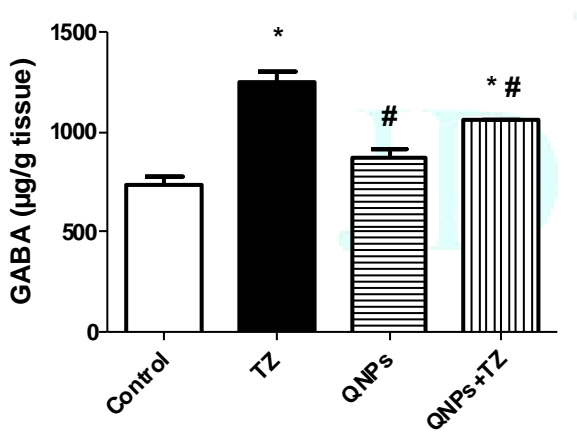

C

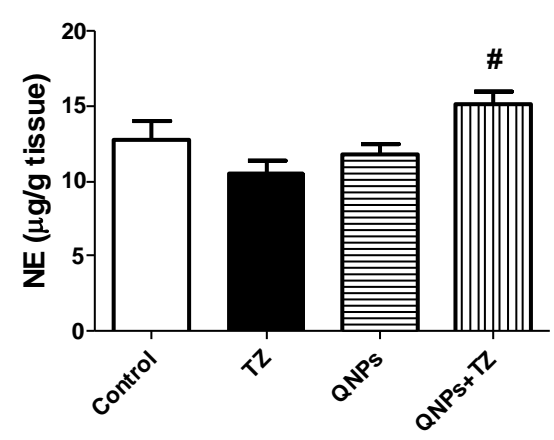

B

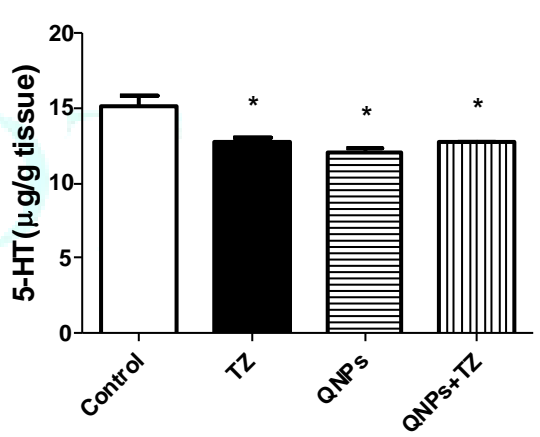

D

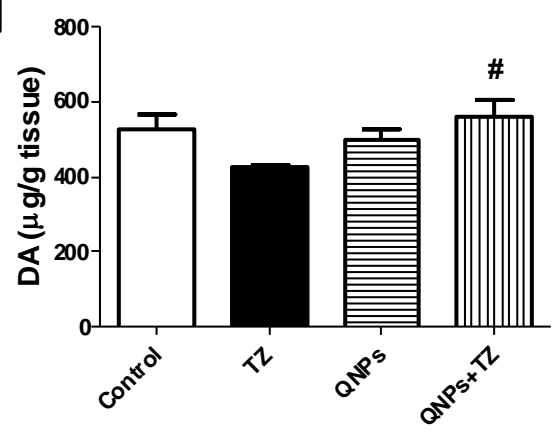

Figure 2: Effects of QNPs (5mg) on cerebellum r-Amino butyric acid (GABA) [A], Serotonin (5-HT) [B], Nor-epinephrine (NE) [C], and Dopamine (DA) [D] of open field behavioral test in $\mathrm{TZ}(50 \mathrm{mg} / \mathrm{kg})$ induced brain injury in rats.

Data represents mean $(\mathrm{n}=8-10) \pm \mathrm{SEM},{ }^{* \#} \mathrm{P}<0.05$ relative to Control \& TZ groups, respectively. Statistical analysis was carried out by one way ANOVA followed by Tukey- Kramer Multiple Comparison Test. 


\section{Immunohistopathological examination of liver and} cerebellum tissues

By using caspase 3 antidote stain for cerebellum, figure (3A) illustrated that $\mathrm{TZ}$ induced apoptosis by significant increasing in expression caspase 3 as compared to control group. Noteworthy, figure (3) revealed that
QNPs or QNPs+TZ improved the apoptosis significantly as compared to $\mathrm{TZ}$ group.

Likewise, figure (3B) illustrated that each of QNPs or QNPs+TZ improved the apoptosis significantly in liver tissues as compared to TZ group.

\section{Fgrre 3}

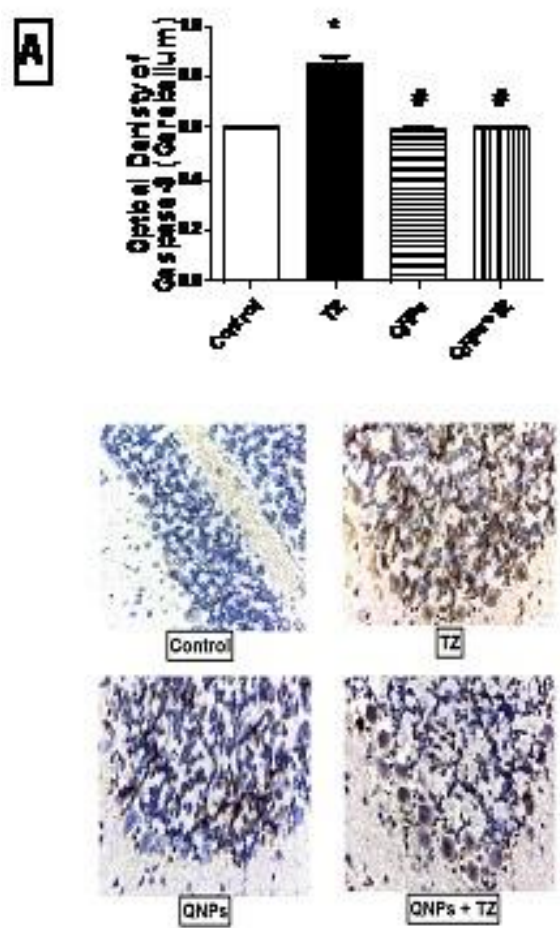

B
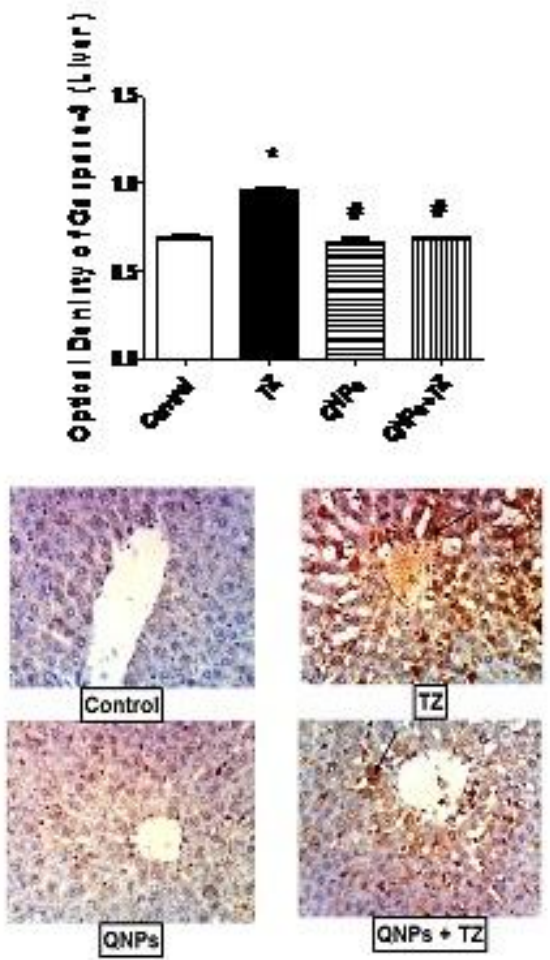

Figure 3: Effects of QNPs (5mg) on optical density of caspase 3 expresssion in cerebellum (A) and liver (B) tissues in $\mathrm{TZ}(50 \mathrm{mg} / \mathrm{kg})$ induced brain-liver injuries in rats.

Data represents mean $(\mathrm{n}=15-20) \pm \mathrm{SEM},{ }^{*}$ \# $\mathrm{P}<0.05$ relative to Control \& TZ groups, respectively. Statistical analysis was carried out by one way ANOVA followed by Tukey- Kramer Multiple Comparison Test.

\section{Histopatholgical examination of liver and cerebellum tissues}

By using $\mathrm{H} \& \mathrm{E}$ stain, figure (4A) illustrated that $\mathrm{TZ}$ induced necrosis and pyknosis of purkinje cells in cerebellum tissues. On the other hand QNPs or
QNPs+TZ made marked improvement in cerebellum tissues as compared to TZ group.

Similarly, figure (4B) showed that liver tissues after administration of TZ, there are induction of Kupffer cells activation, congestion of central vein and sinusoids, and focal hepatic necrosis associated with inflammatory cells infiltration. Alternatively, QNPs or QNPs+TZ made marked improvement in cerebellum tissues as compared to $\mathrm{TZ}$ group. 


\section{Figure 4}
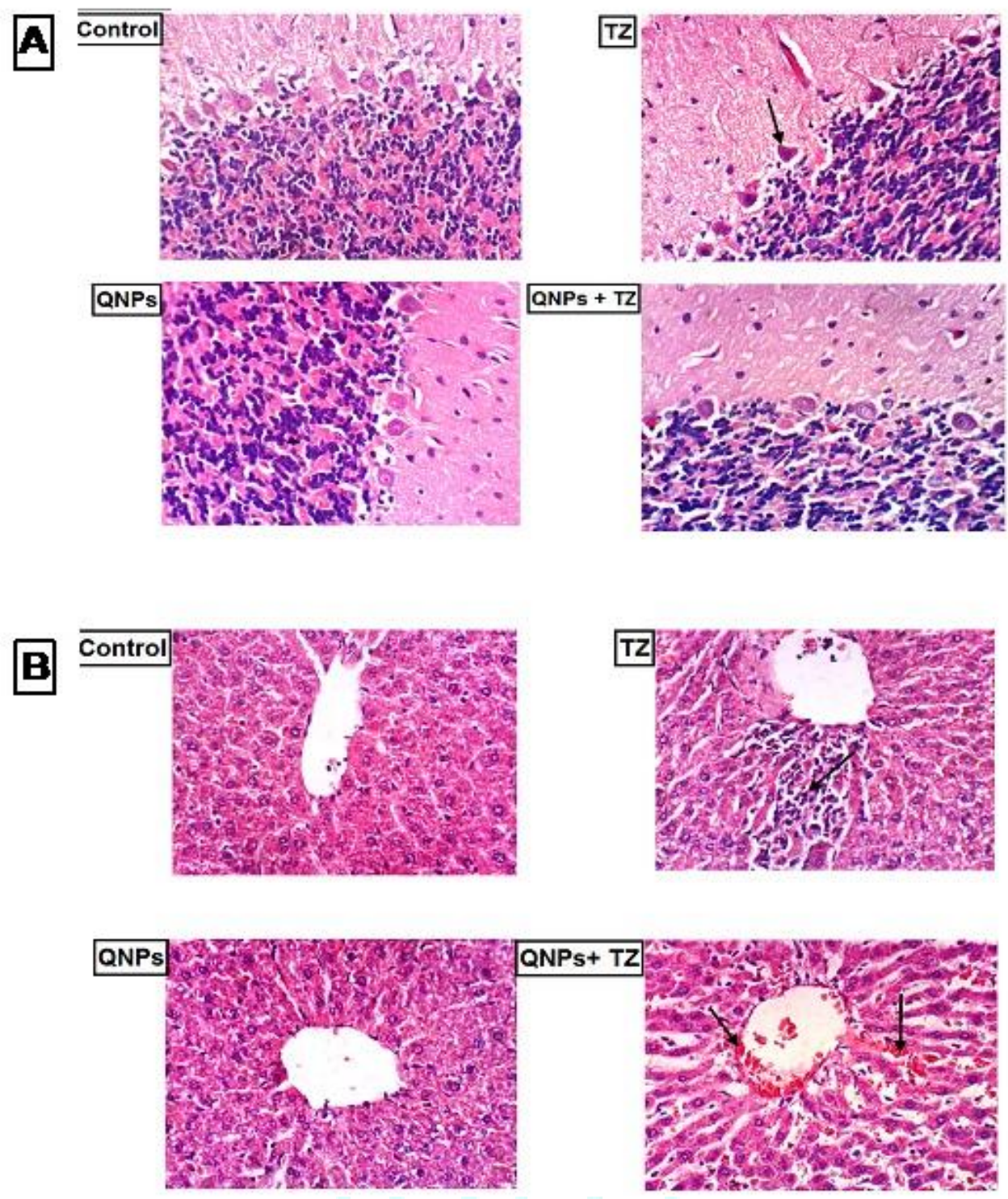

Figure 4: Effects of QNPs (5mg) on histopathological changes in cerebellum (A) and liver (B) tissues in TZ (50 $\mathrm{mg} / \mathrm{kg}$ ) induced brain-liver injuries in rats. Photomicrographs of rat cerebellum and liver sections stained with H\&E (X400).

\section{DISCUSSION}

Food additives, considered as xenobiotic, have a significant effect in currently abundant and nourishing food sources, and allow people to be pleased. Really, they may have several metabolites, such as monosodium glutamate and nitrous compounds that are found to be carcinogens ${ }^{48}$.

Noteworthy, the current study revealed that administration of chosen dose of $\mathrm{TZ}$ caused marked raise in latency time, as well decrease in ambulation frequency, grooming frequency, and rearing frequency of open field behavioral test. These indicated anxietyand depression-like behaviors in rats and these data were in conflict with the previous study ${ }^{49}$. We suggested that altered apoptotic gene expressions or damage related to cerebellum were involved. On the other hand, treatment with QNPs improved these TZ deleterious effects as it has anti-apoptotic effect ${ }^{\mathbf{5 0}}$.
In this, $\mathrm{TZ}$ caused a significant increase in the body weight compared to normal control group. Indeed, an increase in the body weight over $20 \%$ above the mean body weight is considered as obesity ${ }^{\mathbf{5 1}}$. Similar results have also been reported ${ }^{\mathbf{5 2}, 53}$. Meanwhile, using of QNPs as treatment improved the body weight.

Additionally, TZ declined $\mathrm{Hb} \%$, RBCs count and HCT\% significantly as in previous studies ${ }^{\mathbf{5 4}, \mathbf{5 5}}$. These changes may be due to the prevention of red blood cell synthesis via inhibition of erythropoisis in the bone marrow ${ }^{\mathbf{5 6}}$ as well as increase fragility and progressive destruction of RBCs due to binding of free radicals produced by $\mathrm{TZ}$ 57. Conversely, QNPs administration recovered blood markers and might be due to antioxidant activity of QNPs ${ }^{58}$.

In fact, $\mathrm{TZ}$ treatment affected liver function tests. These results may be attributed to hepatocellular damage caused by the toxic effect of TZ which was indicated 
by histopathological examination. Alternatively, there were current recovers in AST and ALT levels and ALP activity in QNPs + TZ group which may be due to improvement in liver tissue as appear by histopathological examination.

Herein, TZ induced harm regarding to lipid profile as another study ${ }^{59}$. On the other hand, QNPs improved the lipid profile. Igarashi and Ohmuma, (1995) ${ }^{\mathbf{6 0}}$ stated that, quercetin decreased serum total cholesterol level in rats through increasing its fecal excretion. In addition, quercetin reduces de novo synthesis of fatty acids and consequently cholesterol biosynthesis and lipoproteins formation ${ }^{\mathbf{6 1}}$.

Herein, ROS, MDA and PC levels and MPO activity increased significantly in liver and brain tissues accompanied with a significant decrease in the activity of GPx after administration of TZ, as other studies ${ }^{\mathbf{6 2}, \mathbf{6 3}}$. In addition, the measurement of $\mathrm{PC}$ has some advantages as the relative early formation and the relative stability of carbonylated proteins ${ }^{64}$. In contrast QNPs showed valuable effects on liver and brain oxidation by enhancing antioxidant enzyme activity and decreasing pro-oxidant effect ${ }^{25}$.

\section{REFERENCES}

1- Toledo MCF. Aditivos Alimentares in Fundamentos deToxicología. Atheneu.Brasil. 1996; p. 405-39.

2- Toledo MCF. Regulamentação deUso de Corantes Naturais. Arch. Latinoam Nutr., 1999; 49(Supl 1)67-70.

3- Hirschbruch MD, Torres EAFS. Toxicologia de Alimentos: Uma Discussão. Hig.Alim ., 1998; 12(53):21-25.

4- Sandler RS. Diet and Cancer: Food Additives, Coffee and Alcohol. Nutr. Cancer, 1983; 4(4):273-9.

5- Volpi EL. Aditivos Alimentares. Aliment.Nutr., 1985; 6(23):40-44.

6- Hurtado RM. Reaccionesadversas a alimentos y susaditivos. Pediatr Dia., 1998; 14(3):128-31.

7- Sasaki YF, Kawaguchi S, Kamaya A, Ohshita M, Kabasawa $\mathrm{K}$, Iwama K, Taniguchi K, Tsuda S. The comet assay with 8 mouse organs: results with 39 currently used food additives. Mutat. Res., 2002; 519:103-119.

8- Preussmann R. Toxicological aspects of food safetyCarcinogenicity and mutagenicity. Arch. Toxicol. Suppl, 1978; 1: 69-84.

9- Fergunson LR. Natural and man-made mutagens and carcinogens in the human diet. Mut. Res., 1999; 433(1-2):110

10- Jones R, Ryan AJ, Wright SE. The Metabolism and Excretion Of Tartrazine. Food CosmetToxicol., 1964; 2:447.

11- Roxon JJ, Ryan AJ, Wright SE. Enzymatic reduction of tartrazine by Proteus vulgaris from rats. Food CosmetToxicol., 1967; 5:645.

12- Chung KT, Stevens SEJr, Cerniglia CE. The reduction of dyes by the intestinal microflora. Crit. Rev. Microbiol., 1992; 18(3):175-190.

13- Maekawa A, Matsuoka C, Onodera H, Tanigawa H, Furuta K, Kanno J, Jang JJ. LacK of Carcinogenecity of Tartrazine (FD \& C YELLOW N ${ }^{\circ}$ ) in the F344 Rat. Food Chem. Toxicol., 1987; 25(12):891-896.

14- Geller M. Aditivos: Alergia e Idiossincrasia .J. bras.Med., 1987; 53(2):56-60.

15- Marisol LMG, Modesto OS. Estudio de la frecuencia de urticaria y angiodemainducidosporaditivos de alimentos. Alerg.Imunol.Clin., 1989; XXXVI:1. Enero-febrero.

16- Devlin J, David TJ. Tartrazine in atopic eczema. Arch Des Child, 1992; 67:709-711.
Regarding to AChE activity, TZ administration caused significant inhibition in its activity in the brain tissue. While, QNPs showed improvement in AChE activity. Moreover, TZ administration led to decrease in 5-HT level in cerebellum which may be due to free radicals that generated when azo dyes metabolized by intestinal bacteria. These free radicals inhibited formation of adenosine triphosphate ATP that cause reduces synthesis or re-uptake of neurotransmitter in the presynaptic cell 65. Additionally, elevated GABA level by TZ may be due to inhibition of the voltage-dependent calcium channels, whereas treatment with QNPs improved the GABA level in cerebellum.

\section{CONCLUSION}

These protective effects of QNPs against TZ induced hepato- and neuro-toxicities may be due to antioxidant, anti-inflammatory and anti-apoptotic effects.

\section{Acknowledgment}

The authors are grateful to Dr. Kawkab Abdel-Aziz, Professor of Pathology, Faculty of Veterinary Medicine, Cairo University, for her helpful guide in histopathological examination.
17- Corder EH, Buckley CE. Aspirin, Salicylate and Tartrazine Induced Bronchonstriction. Safe doses and Case Definition in Epidemiological Studies. J. ClinEpidemiol, 1995; 48(10):1269-1275.

18- Wuthrich B. Adverse reactions to food additives. Ann. Allergy., 1993; 71(4):379-384.

19- Collins TFX, Black TN, Brown LH, Bulhack P. Study of the teratogenicpotencial of FD \& C Yellow $\mathrm{n}^{\circ} 5$ when given by gavage to rats. Food Chem. Toxic., 1990; 28(12):821-827.

20- Reyes FG, Valim MF, Vercesi AE. Effect of organic synthetic food colours on mitocondrial respiration. Food AdditContam., 1996; 13(1):5-11.

21- Koutsogeorgopoulou L, Maravellas C, Methenitou G. Immunological Aspects of the Common Food colorants, Amaranth and Tartrazine. Vet. Hum. Toxicol., 1998; 40(1):14.

22- Walton K, Walker R, Van De Sandt JJM, Castell JV. The Application of In Vitro in the Derivation of the Acceptable Daily Intake of Food Additives. Food Chem Toxicol. 1999; 37:1175-1197.

23- Uzun FG, Demir F, Kalender S, Bas H, Kalender Y. Protective effect of catechin and quercetin on chlorpyrifos-induced lung toxicity in male rats. Food and Chemical Toxicology 2010; 48:1714-1720.

24- ErdenInal M, Kahraman A. The protective effect of flavonol quercetin against ultraviolet induced oxidative stress in rats. Toxicology 2000; 154:21-29.

25- Galati G, Sabzevari O, Wilson JX, O’Brien P. J. Prooxidant activity and cellular effects ofphenoxyl radicals of dietary flavonoids and other polyphenolics. Toxicology 2002; 177:91-104.

26- Pedrielli P, Skibsted LH. Antioxidant synergy and regeneration effect of quercetin, (-)-epicatechin, and $(+)$-catechin on tocopherol in homogeneous solutions of peroxidating methyl linoleate. Journal of Agricultural and Food Chemistry 2002; 50:7138-7144.

27- Palle S, Neerati P. Quercetin nanoparticles attenuates scopolamine induced spatial memory deficits and pathological damages in rats. Bulletin of Faculty of Pharmacy, Cairo University, 2017; 55(1):101-106. 
28- Noyes AA, Whitney WR. The rate of solution of solid substances in their own solutions. J. Am. Chem. Soc., 1897; 19:930-934.

29- Eraslan G, Saygi S, Essiz D, Aksoy A, Gul H, Macit, E. Evaluation of aspect of some oxidative stress parameters using vitamin $\mathrm{E}$, proanthocyanidin and $\mathrm{N}$ acetylcysteine against exposure to cyfluthrin in mice. Pesticide and Biochemical Physiology 2007; 88:43-49.

30- Khan SM, Kour G. Subacute oral toxicity of chlorpyrifos and protective effect of green tea extract. Pesticide and Biochemical Physiology 2007; 89:118-123.

31- Durak D, Uzun FG, Kalender S, Ogutcu A, Uzunhisarcikli M, Kalender Y. Malathion-induced oxidative stress in human erythrocytes and the protective effect of vitamins $\mathrm{C}$ and $\mathrm{E}$ in vitro. Environmental Toxicology 2009; 24(3):235-242.

32- Sethi P, Jyoti A, Singh R, Hussain E, Sharma D. Aluminiuminduced electrophysiological, biochemical and cognitive modifications in the hippocampus of aging rats. Neurotoxicology, 2008; 29(6):1069-1079.

33- Trinder P. Determination of blood glucose using an oxidaseperoxidase system with a non-carcinogenic chromogen. Journal of clinical pathology, 1969; 22(2):158161.

34- Reitman S, Frankel S. A Colorimetric method for determination of serum glutamic oxaloacetate and glutamic pyrumictransminase. Am. J. Clin. Path.1957; 28:26-34.

35- Belfield A, Goldberg DM. Revised assay for serum phenyl phosphatase activity using 4-amino -antipyrine. Enzyme, 1971; (12):561.

36- Wieland H, Seidel D. A simple specific method for precipitation of low density lipoproteins. Journal of lipid Researsh, 1983; 24(7):904 -909.

37- Burstein MSHR, Scholnick HR, Morfin R. Rapid method for the isolation of lipoproteins from human serum by precipitation with polyanions. Lipid Research, 1970; (11):583-595.

38- Zollner N, Kirsch K. Determination of serum total lipids calorimetrically. Zeitschrift fur die gesamteexperimentelle Medizin. 1962; 135:545.

39- Vrablic AS, Albright CD, Craciunescu CN, Salanik RI, Zesel $\mathrm{SH}$. Altered mitochondrial function and over generation of reactive oxygen species precede the induction of apoptosis by 1-O-octadecyl-2-methyl-racglycero-3-phosphocholine in p53-defective hepatocytes. Federation of Americon Societies for Experimental Biology journal, 2001; (15), 1739-1744.

40- Uchiyama M, Mihara M. Determination of malonaldehyde precursor in tissue by thiobarbituric acid test. Anal.Biochem., 1978; (86):271-278.

41- Brigelius-Flohe R.Tissue-specific functions of individual glutathione peroxidases. Free Radic Biol Med. 1999; 27:95165.

42- Smerjac SM, Bizzozero OA. Cytoskeletal protein carbonylation and degradation in experimental autoimmune encephalomyelitis. Journal of neurochemistry, 2008; 105(3):763-772.

43- Bradley PP, Priebat DA, Christensen RD, Rothstein G Measurement of cutaneous inflammation: estimation of neutrophil content with an enzyme marker. Journal of Investigative Dermatology. 1982; 78(3):206-209.

44- Ellman GL, Courtney KD, Andres V. Featherstone, RM, A new and rapid colormetric determination of acetylchlolinestraseactivity.Biochem.pharmacol. 1961; (7):88- 95

45- Gorun V, Proinov I, Baltescu V, Balaban G, Barzu O. Modified Ellman procedure for assay of cholinesterase in crude enzymatic preparations. Anal.Biochem. 1978; (86):324326.

46- Ciarlone AE. Further modification of a fluorometric method for analyzing brain amines. Microchemical journal, 1978; 23(1):9-12.

47- Rato L, e Silva FC, Costa A, Antunes C. Analysis of pancreas histological images for glucose intolerance identification using imagej-preliminary results. Paper presented at the 4th Eccomas Thematic Conference on Computational Vision and Medical Image Processing; 2013.

48- Amin KA, Al-Shehri, FS. Toxicological and safety assessment of tartrazine as a synthetic food additive on health biomarkers: A review. African Journal of Biotechnology, 2018; 17(6):139-149.

49- Gao Y, Li C, Shen J, Yin H, An X, Jin H. Effect of food azo dye tartrazine on learning and memory functions in mice and rats, and the possible mechanisms involved. Journal of food science, 2011; 76(6):T125-T129.

50- Baltaci BB, Uygur R, Caglar V, Aktas C, Aydin M, Ozen OA.Protective effects of quercetin against arsenic-induced testicular damage in rats. Andrologia, 2016; 48(10):12021213.

51- Chatterjea MN, Rana Shinde. Textbook of Medical Biochemistry Jaypee Brothers Medical Publishers. 2002; 601-613.

52- Sharma A, Goyal RP, Chakravarty G, Sharma S. Haemotoxic effects of chocolate brown. A commonly used blend of permitted food colour on Swiss albino mice. Asian J. Environ. Sci. 2005; 19:93-103.

53- Osman MA, Afifi A, Hussien RM, Kamilia BA, Salah SH. Long term biochemical and genotoxicity studies of four synthetic food and drug colourant in mice. Bull. Fac. Pharm. 1995; 33:12-13.

54- Przybylska M, Faber M, Zaborowski A, Swietoslawski J, Bryszewska M. Morphological changes of human RBC induced by cholesterol sulphate. Clin Biochem. 1998; 31(2):73-79.

55- Taib IS, Budin SB, Ain SMSN, Mohamed J, Louis SR, Das $\mathrm{S}$, Hidayatulfathi O. Toxic effects of Litsea elliptica Blume essential oil on red blood cells of Sprague-Dawley rats. Journal of Zhejiang University Science B 2009; 10(11):813.

56- Al-Shinnawy MS, Elkattan NA. Assessment of the changes in some diagnostic parameters in male albino rats fed on an Azo Dye. Int. J. Eenv. Sci. Eng, 2013; 4:85-92.

57- Balani T, Agrawal S, Thaker AM. Hematological and biochemical changes due to short-term oral administration of imidacloprid. Toxicology International. 2011; 18(1):2-4.

58- Anjaneyulu M, Chopra K. Quercetin, an anti-oxidant bioflavonoid, attenuates diabetic nephropathy in rats. Clinical and Experimental Pharmacology and Physiology 2004; 31:244-248.

59- Aboel-Zahab H, El-Khyat Z, Sidhom G, Awadallah R, Abdel-Al W, Mahdy K. Physiological effects of some synthetic food colouring additives on rats. Boll Chim Farm 1997; 136(10):615-27.

60- Igarashi K, Ohmuma M. Effects of isorhamnetin, rhamnetin, and quercetin on the concentrations of cholesterol and lipoperoxide in the serum and liver and on the blood and liver antioxidative enzyme activities of rats. Biosci Biotechnol Biochem. 1995; 59:595-601.

61- Gnoni GV, Paglialonga, G, Siculella L. Quercetin inhibits fatty acid and triacylglycerol synthesis in rat-liver cells. Eur J Clin Invest. 2009; 39:761-768.

62- Verma VC, Kharwar RN, Strobel GA. Chemical and functional diversity of natural products from plant associated endophytic fungi. Nat ProdCommun. 2009; 4(11):1511-1532.

63- Aly AH, Debbab A, Kjer J, Proksch P. Fungal endophytes from higher plants: a prolific source of phytochemicals and other bioactive natural products. Fungal diversity, 2010; 41:1-16.

64- Dalle-Donne I, Rossi R, Giustarini D, Milzani A, Colombo R.Protein carbonyl groups as biomarkers of oxidative stress. Clinica chimica acta, 2003; 329(1-2):23-38.

65- Bawazir AE. Effects of Food Colour Allura Red (No. 129) on some neurotransmitter, Antioxidant Functions and Bioelement Contents of Kidney and Brain Tissues in male albino Rats. Life Science Journal, 2016; 13(12). 